\title{
Experimental Study of the Filling Effect of MICP Microbial Grouting in Silt
}

\author{
Zhaoyang XU \\ College of Civil Science and Engineering \\ Yangzhou University \\ Yangzhou, Jiangsu, China \\ E-mail: zhaoyang_xu@aliyun.com \\ Yishan PANG \\ College of Civil Science and Engineering \\ Yangzhou University \\ Yangzhou, Jiangsu, China
}

\author{
Tingchun BAI \\ College of Civil Science and Engineering \\ Yangzhou University \\ Yangzhou, Jiangsu, China
}

Feng ZHOU

College of Civil Science and Engineering

Yangzhou University

Yangzhou, Jiangsu, China

\author{
Jianzhang HUANG \\ College of Civil Science and Engineering \\ Yangzhou University \\ Yangzhou, Jiangsu, China
}

\begin{abstract}
MICP (Microbial Induced Carbonate Precipitation) technology was used for silt biological grouting to improve soil. First, the changes of calcium carbonate precipitation volume with different concentrations of $\mathrm{Ca}$ /urea reaction solution or in different inducing environments (such as culture, filtrate and thallus) were studied after the filtrate and thallus were separated from the Sporosarcina pasteurii broth. The microbial induced carbonate precipitation mechanism was also analyzed. Then, the crystalline morphology of precipitation under different concentrations of the reaction solution was researched by SEM and XRD. Finally, the cycle grouting method was used for bio-grouting in silt, from which the distribution and amount of change regarding pores in silt were analyzed through a CT scan before and after grouting. The results of this study show that the calcium carbonate precipitation was the result of urease action. Precipitation contained both vaterite and calcite. The study also found that $\mathrm{Ca} /$ urea concentration changes could affect the crystalline morphology of calcium carbonate. MICP could be realized in porous medium like silt by step cycle grouting. The precipitation and filling effect was increased by the number of bio-grouting. After grouting five times, soil porosity decreased from $27.27 \%$ to $11.34 \%$. This study concludes that this method has good application potential for silt foundation reinforcement.
\end{abstract}

Keywords-MICP; sporosarcina pasteurii; carbonate precipitation; silt grouting; $C T$ scan; precipitation and filling

\section{INTRODUCTION}

In cyclical loads such as earthquakes, saturated silt or sand soils are prone to liquefaction, resulting in the loss of foundation bearing capacity, uneven subsidence, slippery slope flow occurrences, etc., which can lead to various engineering structural damage phenomena such as tilting, cracking and even collapse, ultimately resulting in serious consequences[1]. There are some disadvantages to traditional liquefied foundation physics strengthening methods such as foundation replacement, pile and dynamic compaction, such as a low technology economy and a higher construction cost[2]. Geotextile reinforcement technology and chemical grouting technology based on either inorganic or organic adhesive often have the problem of insufficient durability, and may more easily cause environmental pollution[3]. Furthermore, the process of chemical grouting itself regularly causes environmental pollution, as evident by the fact that the use of synthetic materials for chemical grouting technology has been banned in many countries.

Microbial technology has development rapidly in recentyears, infiltrating the field of civil engineering, and itsmicro-grouting technology has been recently applied to microbial metallogeny[4]. Soil reinforcement by microbial grouting technology is mainly based on the mechanism of biomineralization of MICP[5]. MICP is a process to generate calcium carbonate with the work of specific bacterial metabolites and surrounding nutrients. Calcium carbonate (MICP) can fill the voids between soil and is also a good soil particle cementing material used to improve the strength of the soil, reduce the soil porosity ratio, reduce the soil permeability coefficient, etc. Compared with traditional foundation treatment methods, bio-grouting technology has the advantages of low grouting pressure, long transmission distance, small disturbance, short construction period and low energy consumption, which serves as a frontier topic for liquefied foundation reinforcement[6].

Currently, the MICP grouting technique is mainly used for treatment of sand based on Bacillus[7-9], with relatively less research concerning silt $[10,11]$. In this paper, Sporosarcina pasteurii was used in silt bio-grouting tests. 
First, the mechanism of bacterial-induced carbonate precipitation was studied, and the crystalline morphology of calcium carbonate under different conditions were compared. Then, the sediment and filling effects were studied through silt column bio-grouting.

\section{BACILLUS INDUCED CALCIUM CARBONATE PRECIPITATION}

\section{A. Biological Tests}

In order to study the feasibility and effect of calcium carbonate precipitation induced by different ways, and measure the effect of the reaction solution concentration on the precipitation effect, $100 \mathrm{ml}$ of NH4-YE medium inoculated with $1 \%$ bacteria was cultured for a continuous 39 hours in a $30{ }^{\circ} \mathrm{C}$ shaking table at $180 \mathrm{r} / \mathrm{min}$ to get a standard bacteria solution (A-1). The reaction solution was composed of urea and calcium chloride solution in a volume ratio of 1:1.

Secondly, high speed centrifuge was used for A-1 bacteria liquid to separate the thallus and filtrate. The filtrate was then passed through a sterile $0.22 \mu \mathrm{m}$ filter to get germfree filtrate (A-2). The thallus at the bottom of the centrifuge tube was added to $0.9 \%$ of the $100 \mathrm{ml}$ saline to get a pure thallus solution (A-3). Then, $100 \mathrm{ml}$ reaction solution of $1 \mathrm{~mol} / 1,2 \mathrm{~mol} / \mathrm{land} 4 \mathrm{~mol} / \mathrm{l}$ was quickly added to $100 \mathrm{ml}$ of the A-1, A-2 and A-3 solutions, respectively, and the sediment calcium carbonate process was observed.

Fig. 1 shows the reaction in the test tubes after adding different concentrations of the reaction solution. Turbidity showed immediately in A-1 and A-2, but did not change in the A-3 solution. Accordingly, it can be drawn that both the bacterial solution and the filtrate could induce the production of calcium carbonate. Bacillus inducing the calcium carbonate formation is the result of the bacterial metabolites-urea enzyme action. Later, adding $100 \mathrm{ml}$ of the NH4-YE medium to the A-3 solution, and letting it standing at room temperature for 48 hours, precipitation was produced, as shown in Fig. 2.This indicated that the thallus had good biological activity, which provides theoretical support for the feasibility of a step-by-step bio-grouting in silt. However, according to the test observations, the volume of precipitation did not increase with the reaction solution concentration.

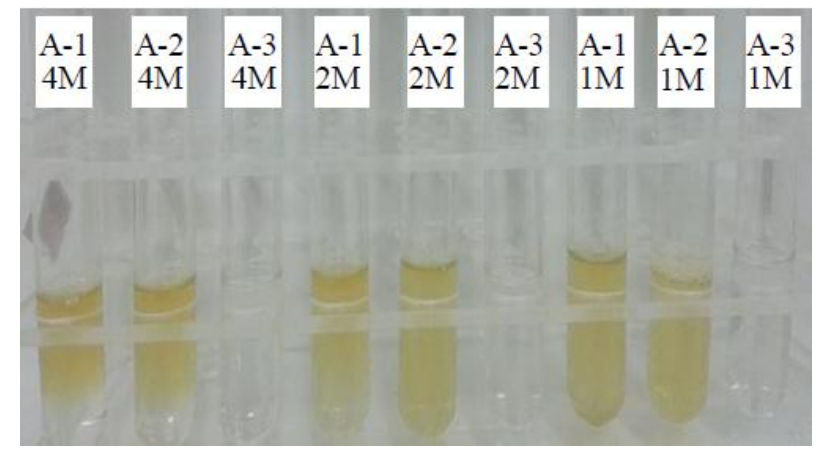

Figure 1. Bacteria liquid filtrate and pure thallus solution.

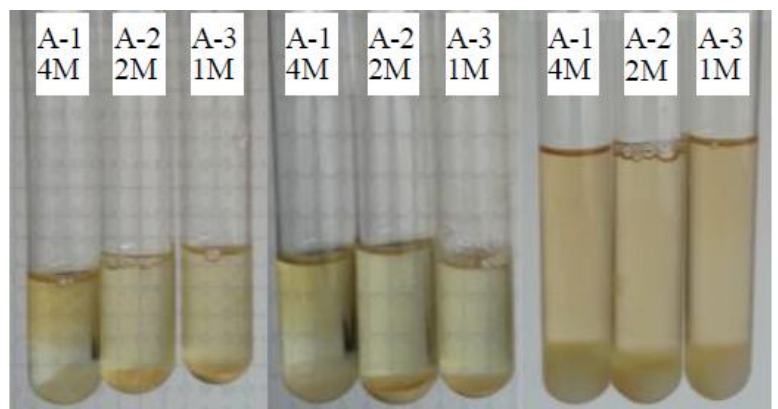

Figure 2. Bacteria liquid, filtrate and pure bacteria solution induced calcium carbonate precipitation after $48 \mathrm{~h}$.

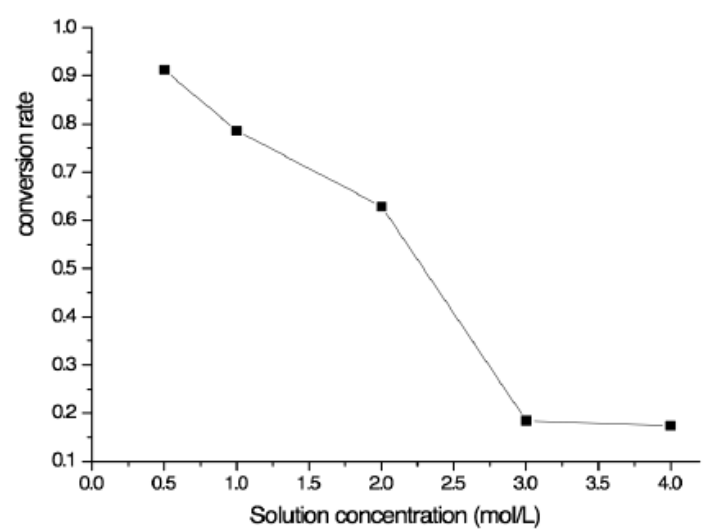

Figure 3. Calcium carbonate conversion rate in different concentration reaction solution.

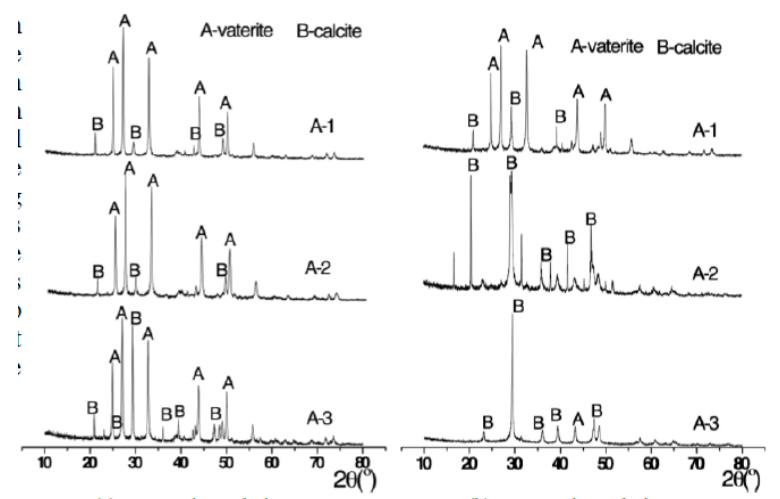

(a) $1 \mathrm{M}$ reaction solution

(b) $2 \mathrm{M}$ reaction solution

Figure 4. XRD spectrum of calcium carbonate sediments

\section{B. Analysis of the Amount of Calcium Carbonate Precipitation}

The method of acid-base titration was adopt for the analysis of the conversion rate of $\mathrm{Ca}^{2+}$ to $\mathrm{CaCO}_{3}$, calculating the amount of calcium carbonate in the sediments. The conversion rate is equal to the measurement quality of the calcium carbonate or theoretical precipitated calcium carbonate quality.

Calcium carbonate conversion rates in different reaction solution concentrations are shown in Fig. 3. The conversion 
rate of calcium carbonate reduced as the reaction solution concentration increased, and when the concentration was greater than $2 \mathrm{~mol} / \mathrm{l}$, the conversion rate would decreased sharply, indicating that a higher reaction solution concentration could inhibit the action of the urinary enzyme. Therefore, the reasonable reaction solution concentration should be taken as 1 2mol/l.

\section{SEM and XRD Analysis of Calcium Carbonate Precipitation}

Scanning Electron Microscopy (S-4800) and X-ray Diffraction (D8 Advance) were used to analyze the precipitation and study the characteristics of calcium carbonate precipitation under different conditions. Fig. 4 shows XRD patterns of sediments produced in A-1, A-2 and A-3 reaction solution, respectively as $1 \mathrm{~mol} / \mathrm{l}$ and $2 \mathrm{~mol} / \mathrm{l}$. The XRD spectrum analysis shows that calcium carbonate precipitation, under different circumstances, generally contained both vaterite and calcite, but when the reaction solution concentration was $2 \mathrm{M}$, the crystal was dominated by calcite.

Fig. 5 is SEM images of calcium carbonate precipitation under different concentrations of the reaction solution. It can be seen that the precipitation in the $1 \mathrm{M}$ solution, with a higher density than that of the $2 \mathrm{M}$ solution, almost condensed into pieces. But calcium carbonate crystal morphology was more obvious in the $2 \mathrm{M}$ solution, showing flower-shaped structures more stable than those in the $1 \mathrm{M}$ solution.

\section{SATURATED SOIL COLUMN BIO-GROUTING AND FILLING EFFECT ANALYSIS}

\section{A. Grouting Device and Method}

After standing at room temperature $\left(26 \pm 2{ }^{\circ} \mathrm{C}\right)$ for 24 hours, the bio-grouting experiment was carried out in a $150 \mathrm{ml}$ syringe, with an inner diameter of $40 \mathrm{~mm}$, a length of about $150 \mathrm{~mm}$, and a soil column in the middle of the tube measuring $80 \mathrm{~mm}$ high. The grouting schematic and physical devices are shown in Fig. 6. First, continuous injection of a certain amount of deionized water almost saturated the silt column (the silt column can be saturated with $30 \mathrm{ml}$ water by measurement). Then, a step-grouting method is used in this experiment, which was divided into two steps. The first step involved pouring $30 \mathrm{ml}$ of the bacteria liquid, cultivated for $39 \mathrm{~h}$, into the silt column. The second step was pouring about $30 \mathrm{ml}$ of the $\mathrm{Ca} /$ urea mixed reaction solution. We repeated the previous steps several times after 24hours when the microbial activity in the system reduced to a certain degree. In the experiment, the amount of each reaction solution was controlled, measuring about $30 \mathrm{ml}$, and the concentration of the reaction solution was controlled at $2 \mathrm{M}$.

In the experiment, the sample B-2 was grouted three times, the sample B-3 was grouted 5 times, and B-1 was a plain soil sample. 2.

\section{B. CT scan Analysis of Grouted Silt}

The effect of the calcium carbonate precipitation distribution induced by microbial in situ grouting depends, to some extent, on whether the pore volume can be effectively occupied by the material. Through a CT scan of specimens by grouting, changes in the compactness of silt can be analyzed by porosity, pore number, pore size and pore spatial distribution at the meso-scale. Thus, the distribution effect of microbial induced calcium carbonate precipitation can be compared before and after grouting as well as under different grouting times.

In the experiment, the B-2, B-3 and B-1 samples, which were completed by grouting, were put into the drying oven $\left(30{ }^{\circ} \mathrm{C}\right)$ for $24 \mathrm{~h}$. Then, we intercepted a section measuring $35 \mathrm{~mm}$ high and $20 \mathrm{~mm}$ in diameter from the middle part of each sample to analyze by Y.CT precision S-type X-Ray CT scanning system. As can be seen from Tab. 3, the sample porosity decreased after grouting and as the number of grouting increases, the reducing effect becomes more obvious.
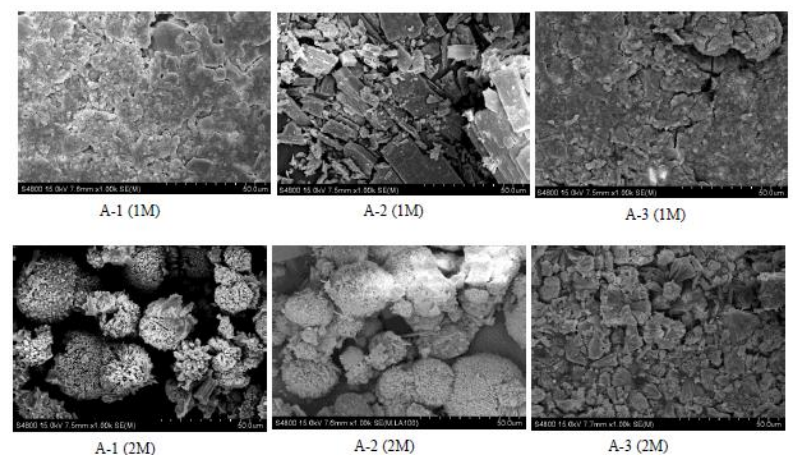

Figure 5. SEM images of calcium carbonate sediments.

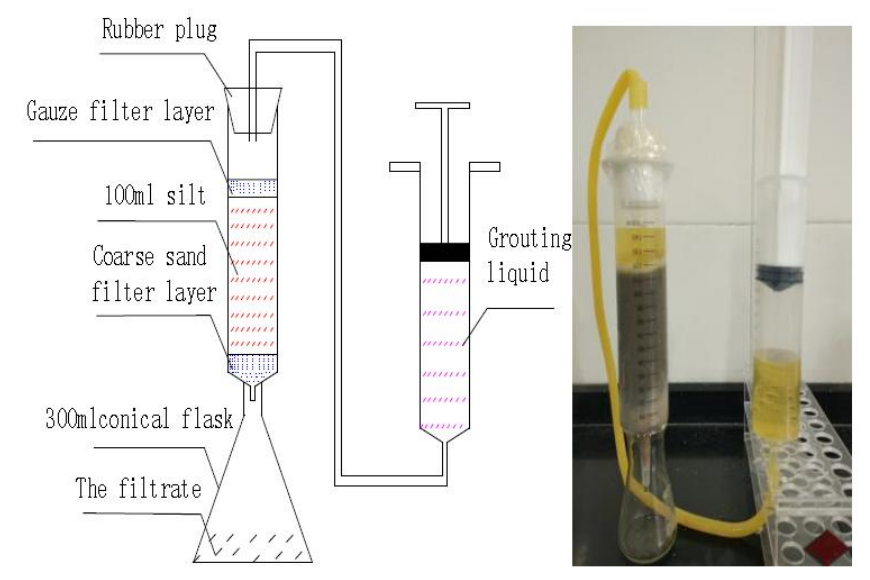

Figure 6. Simplified model of biological grouting (left) and grouting physical map (right).

Figures 7-9 are the CT scan images of the samples. The three-dimensional pore space distribution maps are shown in Figures 7(a)-9(a). To distinguish pore size, the pores are marked respectively from largest to smallest with red orange - green - blue. As can be seen from the contrast, the 
inner holes of the non-grouting soil are larger than that of the grouting soil. The reduction of large pores after multiple grouting further proves the feasibility of filling silt with microbial-induced calcium carbonate precipitation. From the CT cross-sectional and longitudinal section of B-2 and B-3 can be found that the pore distribution is not uniform, and that the small pore distribution is relatively large near the outer edge, but most of the large pore distribution is in the central area. The reason why the filling effect of calcium carbonate on the edge sediment is better may be that the slurry is easier to infiltrate along the tube wall of the syringe. Accordingly, providing a proper slurry infiltration channel has a great influence on the distribution of grouting.

\section{CONCLUSION}

- Carbonate mineralization bacteria induced calcium carbonate precipitation is mainly the result of an urease enzyme role. The amount of precipitation does not increase as the $\mathrm{Ca} /$ ureare action solution concentration increases. Instead, a reaction concentration higher than $3 \mathrm{M}$ will inhibit urease's role. As a result, the reasonable reaction solution concentration should be taken as 1 2mol/l.

- Sporosarcina pasteurii thallus has good physical activity. It can continue producing the urease enzyme by adding nutrition, which provides theoretical support for the feasibility of repeated grouting.

- The reaction solution (urea and calcium chloride solution mixed in a volume ratio of $1: 1$ ) concentration and changes in the microbial inducing environment can affect calcium carbonate crystalline morphology. Calcium carbonate crystal morphology is more apparent in the $2 \mathrm{M}$ reaction solutions, which contain more calcite crystals.

- Using MICP technology for grouting in silt, which first infuse the microbial solution, and then infuse the $\mathrm{Ca}$ /urea mixed reaction solution, can realize the sedimentary and filling of induced calcium carbonate in a porous medium. Furthermore, with the increase of the number of groutings, the sedimentary and filling effect is more obvious.
Therefore, MICP technology has good application potential for silt foundation reinforcement.

\section{ACKNOWLEDGEMENTS}

This work was supported by National Natural Science Foundation of China (Project No.51278446) and Science and technology project of Jiangsu Province (BY2016069-05).

\section{REFERENCES}

[1] Tina M. Niemi, Aaron N. Ferris, and Geoffrey A. Abers Investigation of Microearthquakes, Macroseismic Data, and Liquefaction Associated with the 1867 Wamego Earthquake in Eastern Kansas [J]. Bulletin of the Seismological Society of America, Vol. 94, No. 6, 2004, pp. 2317-2329.

[2] Yu Huang, Zhuoqiang Wen. Recent developments of soil improvement methods for seismic liquefaction mitigation $[\mathrm{J}]$. Natural Hazards, Vol.76, No.3, 2015, pp. 1927-1938.

[3] YANG Zuan. Research on Mechanism and Performance of High-strength Microbial Mortar. [D].Tsinghua University,2013.

[4] Van Paassen LA. Biogrout, ground improvement by microbial induced carbonate precipitation[D]. Delft University of Technology, 2009.

[5] DeJong J, Mortensen B, Martinez B et al. Bio-mediated soil reinforcement $[\mathrm{J}]$. Ecological Engineering, Vol.36, No.2, 2010, pp.197-210.

[6] CHENG Xiao-hui, MA Qiang, YANG Zuan, et al.Dynamic response of liquefiable sand foundation improved by bio-grouting $[\mathrm{J}]$. Chinese Journal of Geotechnical Engineering, Vol.35, No.8, 2013, pp. 1486-1495.

[7] Whiffin V, Van Paassen L, Harkes M. Microbial carbonate precipitation as a soil improvement technique $[\mathrm{J}]$. Geomicrobial, Vol.24, No.5, 2007, pp.417-423.

[8] Al Qabany A,Soga K,Effect of chemical treatment used in MICP on engineering properties of cemented soil.Geotechnique, Vol.63, No.4, 2013, pp.331-339.

[9] B.C. Martinez, J.T. DeJong, T.R. Ginn. Biogeochemical reactive transport modeling of microbial induced calcite precipitation to predict the treatment of sand in one dimensional flow $[\mathrm{J}]$. Computers and Geotechnics, Vol.58, No.5, 2014, pp.1-13.

[10] Xu Zhaoyang, Ma Yaoren, Zhou Feng, et al. Laboratory Tests on the Improvement of Characteristics Of Silt Using Iron Bacteria[J]. JOURNAL OF PURE AND APPLIED MICROBIOLOGY, Vol.7, No.3, 2013, pp.795-799.

[11] Xu Zhaoyang, Zhou Feng, BAI Tingchun, et al. Study on Bioremediation using Iron bacteria for Artificially Polluted Soil with Heavy Metals $\mathrm{Cd} 2+$ or $\mathrm{Cr} 3+[\mathrm{J}]$. JOURNAL OF PURE AND APPLIED MICROBIOLO-GY, Vol.9, No.3, 2015, pp.1899-190

TABLE I. MAIN PERFORMANCE INDEXES OF SILT

Specific gravity of silt particle Gs
Plastic Limit $\omega$ P Liquid Limit $\omega \mathrm{L} \quad$ Plastic Limit Index Ip
Maximum Dry density
g/cm3
Best moisture content wop \%
2.70

$20.5 \%$

$28.9 \%$

8.4

1.52

25.6 
TABLE II. PARTICLE COMPOSITION OF SILT

\begin{tabular}{|c|c|c|c|c|c|}
\hline Grain composition (mm) & $2 \sim 0.5$ & $0.5 \sim 0.25$ & $0.25 \sim 0.075$ & $0.075 \sim 0.005$ & $<0.005$ \\
\hline silt & $0 \%$ & $0.2 \%$ & $16.6 \%$ & $76.3 \%$ & $6.9 \%$ \\
\hline \multicolumn{6}{|c|}{ TABLE III. CT SCAN RESULTS OF SILT } \\
\hline CT sample & $\begin{array}{c}\text { Effective } \\
\text { volume } \mathbf{~ m m}^{3}\end{array}$ & $\begin{array}{c}\text { Pore surface } \\
\text { area } \mathbf{m m}^{2}\end{array}$ & Number of pores & porosity & CT sample \\
\hline B-1 & 1605.1 & 6162.2 & 10297316 & $27.3 \%$ & B-1 \\
\hline B-2 & 1633.9 & 4105.3 & 8030541 & $21.3 \%$ & B-2 \\
\hline B-3 & 1594.0 & 3463.6 & 4017300 & $11.3 \%$ & B-3 \\
\hline
\end{tabular}

